\title{
CD14 Plays a Protective Role in Experimental Inflammatory Bowel Disease by Enhancing Intestinal Barrier Function
}

Stephanie Buchheister, ${ }^{*}$ Manuela Buettner, ${ }^{\star}$ Marijana Basic, ${ }^{*}$ Andreas Noack, ${ }^{\dagger}$ Gerhard Breves, ${ }^{\ddagger}$ Barbara Buchen, Lydia M. Keubler, ${ }^{*}$ Christoph Becker, ${ }^{\S}$ and André Bleich*

From the Institute for Laboratory Animal Science, * Hannover Medical School, Hannover; the Departments of Pharmacology, Toxicology and Pharmacy ${ }^{\dagger}$ and Physiology, ${ }^{\ddagger}$ University of Veterinary Medicine Hannover, Hannover; and Medical Clinic $1,{ }^{\S}$ University of Erlangen-Nürnberg, Erlangen, Germany

Accepted for publication

January 30, 2017.

Address correspondence to André Bleich, Ph.D., Institute for Laboratory Animal Science, Hannover Medical School, Carl-Neuberg-Str. 1, 30625 Hannover, Germany. E-mail: bleich.andre@mh-hannover.de.

\begin{abstract}
Intestinal homeostasis disturbance through intestinal barrier disruption presumably plays a key role in inflammatory bowel disease (IBD) development. Genetic and candidate gene analyses in an Il10-deficient IBD mouse model system identified $C d 14$ as a potentially protective candidate gene. The role of Cd14 in colitis development was determined using dextran sulfate sodium (DSS)-induced acute and an Il10-deficiency-induced chronic model of intestinal inflammation. Intestinal permeability was investigated by fluorescein isothiocyanate-dextran uptake assay, quantitative RT-PCR analysis of tight junction proteins, myosin light chain kinase, and proinflammatory cytokine expression. Immunohistological staining of occludin, Ki-67, NF- $\mathrm{B}$ - $\mathrm{p65}$, and terminal deoxynucleotidyl transferase-mediated dUTP nick-end labeling assay was performed, and intestinal inflammation severity was evaluated histologically. Untreated B6-Cd14 ${ }^{-/-}$mice and wild-type controls did not differ in intestinal barrier function. However, DSS-treated Cd14-deficient and $\mathrm{B} 6-\mathrm{I}\left(10^{-/-} \mathrm{Cd} 14^{-/-}\right.$mice exhibited more severe intestinal barrier disruption, with increased histological scores and proinflammatory cytokine expression, compared to controls. Therefore, Cd14 deficiency did not influence epithelial integrity under steady-state conditions but caused intestinal barrier dysfunction under inflammation. As expected, CD14 overexpression increased barrier integrity. No difference in intestinal epithelial NF- $\kappa B$ translocation was observed between the investigated groups. Intestinal myosin light chain kinase expression decreased in Cd14-deficient mice under steady-state conditions and in the chronic model, whereas no difference was detected in the DSS models. Thus, CD14 plays a protective role in IBD development by enhancing intestinal barrier function. (Am J Pathol 2017, 187: 1106-1120; http://dx.doi.org/ 10.1016/j.ajpath.2017.01.012)
\end{abstract}

Inflammatory bowel disease (IBD) refers to a group of chronic intestinal disorders that predominantly include ulcerative colitis and Crohn disease. The development of inflammation in IBD has been suggested to depend on the patient's genetic background, the microbes present, and environmental factors. ${ }^{1}$ Numerous genetic loci have been shown to be associated with IBD development in humans, as well as in mouse models. ${ }^{2-4}$ The $I l 10$-deficient mouse model is a well-known colitis model. Quantitative trait locus analyses using backcross and N2 populations derived from susceptible and resistant mouse strains have revealed that multiple loci, including cytokine deficiency-induced colitis susceptibility (Cdcs) 1-10, are significantly associated with disease expression. ${ }^{5,6}$ In particular, the $C d 14$ gene at one of

\footnotetext{
Supported by Collaborative Research Center SFB621 (Z1) grants; the German Research Foundation (DFG) grant BL 953/4-1 (A.B.); Hannover Biomedical Research School, Center for Infection Biology, stipend (M.B.); the Collaborative Research Center SFB900 project A4, SFB796 subproject B9 (C.B.), and SFB1181 subproject C05 (C.B.) of the DFG clinical research unit KFO25 (C.B.); and the DFG priority program SPP 1656 (A.B., C.B.).

S.B. and M.B. contributed equally to this work.

Disclosures: None declared.
} 
these quantitative trait loci $(C d c s \sigma)$ has been suggested to be a candidate gene for IBD susceptibility. ${ }^{7}$

Cd14 is constitutively expressed on the surfaces of monocytes, macrophages, dendritic cells, neutrophils, and epithelial cells. $^{8-11}$ It has been shown to be essential for lipopolysaccharide (LPS) signal transduction via Toll-like receptor (TLR) 4 and also to interact with TLR2 for detection of lipoproteins, leading to NF- $\mathrm{KB}$ activation. ${ }^{12,13}$ However, the specific role of CD14 in IBD remains to be elucidated. Recent studies have demonstrated that CD14 is only expressed at a low level in the uninflamed intestine and that it is up-regulated during inflammation. ${ }^{8,14}$ In mice, however, its expression is dependent on the genetic background. Higher CD14 expression in the gut at the mRNA and protein levels has been identified in the $\mathrm{C} 3$ rather than in the B6 genetic background, even under germ-free conditions. ${ }^{7,9}$ Because genetic analyses have demonstrated that $\mathrm{C} 3$ mice carry IBD resistance alleles at this quantitative trait locus, CD14 has been hypothesized to have a protective function in dextran sodium sulfate (DSS)-induced colitis. ${ }^{9}$

IBD development is strongly associated with epithelial barrier dysregulation. Epithelial barrier function is predominantly dependent on tight junction (TJ) proteins, which regulate paracellular and transcellular transport. ${ }^{15}$ Various molecules, such as claudins, occludin, and zonula occludens1 (Zo-1), are involved in maintaining this barrier. ${ }^{15,16}$ However, loss of barrier integrity, initiated by bacteria or by treatment with a chemical, such as DSS, results in bacterial invasion and inflammation. ${ }^{16,17}$ In addition, proinflammatory cytokines, such as tumor necrosis factor (TNF)- $\alpha$ and interferon (IFN)- $\gamma$, cause dysregulation of barrier permeability during inflammation. ${ }^{17}$ Although NF- $\kappa$ B activation via TLR signaling is known to be crucial for the development of intestinal inflammation, ${ }^{18}$ epithelial NF-кB signaling has been shown to enhance intestinal barrier functions. ${ }^{19,20}$

Herein, we demonstrated the effect of CD14 on epithelial barrier integrity under steady-state conditions, as well as in the presence of acute and chronic inflammation. The expression of TJ proteins and the numbers of apoptotic and proliferating cells were examined. Using $\mathrm{Cd} 14^{-/-}$and CD14-overexpressing mice, we have provided evidence that CD14 is pivotal for regulating TJ proteins by reducing proinflammatory cytokine expression. Taken together, our results have demonstrated a protective role of CD14 against intestinal inflammation.

\section{Materials and Methods}

Mice

$\mathrm{C} 3 \mathrm{H} / \mathrm{HeJ}(\mathrm{C} 3), \mathrm{C} 3 \mathrm{H} / \mathrm{HeJBir} .129 \mathrm{P} 2-I l 10^{\text {tmlCgn }}\left(\mathrm{C} 3-I l 10^{-/-}\right)$, C57BL/6J.129P2-Illo tmlCgn+/+ (B6-wt), C57BL/ 6J.129P2-Il10 ${ }^{\text {tmlCgn }} \quad\left(\mathrm{B} 6-I l 10^{-/-}\right), \quad$ C57BL/6J.129S1-

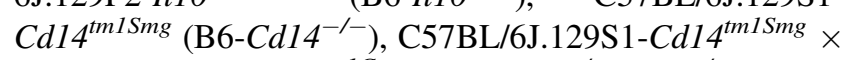
C57BL/6J.129P2-Illo ${ }^{\text {tmlCgn }} \quad\left(\mathrm{B} 6-1 / 10^{-/-} \mathrm{Cd}_{14^{-/-}}\right), \quad$ and
B6.B6D2-TgMt-Cd14M14S (M14S) mice were obtained from the Central Animal Facility (Hannover Medical School, Hannover, Germany). In M14S mice, an upstream metallothionein promoter is associated with the mouse gene of soluble CD14 (sCD14). ${ }^{21}$ CD14 overexpression was induced by feeding these mice $0.5 \mathrm{~mol} / \mathrm{L}$ zinc sulfate in their drinking water for 4 days before DSS treatment. The zinc sulfate administration was sustained over the whole experimental period. CD14 transgenic RNA was present in liver, testes, small intestine, and colon. ${ }^{21}$ This study was conducted in accordance with the German law for animal protection and with the European Directive 2010/63/EU. All experiments were approved by the Local Institutional Animal Care and Research Advisory Committee and were permitted by the local government (number 33.942502-04-11/0499).

\section{TEER Measurement}

To determine the influences of LPS (Sigma Aldrich, St. Louis, MO) and recombinant CD14 (Peprotech, Rocky Hill, NJ) on electrical resistance, CMT93 cells were cultivated on Transwell membranes (polyester membranes, 6 wells, 0.4- $\mu \mathrm{m}$ pore size, 24-mm diameter; Corning Costar Corp., Cambridge, MA) at a density of $1 \times 10^{5}$ cells $/ \mathrm{cm}^{2}$ for 24 hours. The cells were then treated with $100 \mathrm{ng} / \mathrm{mL}$ LPS and $1 \mu \mathrm{g} / \mathrm{mL}$ CD14 for 168 hours, and integrity of the monolayers was analyzed by measuring transepithelial electrical resistance (TEER) with an EndOhm chamber (ENDOHM-6; World Precision Instruments Inc., Sarasota, FL). The experiments were performed in triplicate and were repeated at least twice.

\section{Western Blot Analysis}

CMT93 cells were analyzed for phospho-NF-кB-p65 expression by Western blot analysis half an hour after treatment with LPS and CD14. Therefore, proteins were isolated, separated using a MiniProtean Precast gel (4\% to $15 \%$ polyacrylamide; Biorad, Hercules, CA) and transferred to a nitrocellulose membrane (Millipore, Billerica, MA). As phosphorylation of NF-kB-p65 on Ser536 was shown to increase NF- $\mathrm{BB}-$ p65 activity, ${ }^{22}$ an anti-phospho-P65 primary antibody (clone 93H1; Cell Signaling, Cambridge, UK) was used. Furthermore, a directly labeled anti-actin antibody (Abcam, Cambridge, UK) was used. As a secondary antibody, a horseradish peroxidase-linked anti-rabbit antibody from Cell Signaling was used.

\section{ECN Colonization of Germ-Free Mice}

Escherichia coli Nissle $1917(E c N)$ of the serotype O6:K5:H1 was grown overnight at $37^{\circ} \mathrm{C}$. The overnight culture was diluted 1:500, grown, harvested at the late logarithmic phase after reaching an OD at $600 \mathrm{~nm}$ of 1 (approximately $10^{9}$ colony-forming units $/ \mathrm{mL}$ ), and 
centrifuged. Then, the pellet was redissolved in $100 \mu \mathrm{L}$ sterile phosphate-buffered saline and administered by oral gavage. The control mice received phosphate-buffered saline only. Inoculation was performed under sterile conditions. The mice were sacrificed by carbon dioxide inhalation followed by exsanguination after 72 hours after infection.

\section{Colony-Forming Units}

Colony-forming units were counted after 72 hours after infection in the cecum and colon contents, mesenteric lymph nodes, spleen, and liver. To determine the number of bacteria, the samples were weighed and homogenized in sterile phosphate-buffered saline. The homogenates were serially diluted in phosphate-buffered saline, and each dilution was cultured on a blood agar plate and grown at $37^{\circ} \mathrm{C}$ in an incubator for 24 hours. The number of colonies was counted and presented as the number of bacteria per gram of tissue or content.

\section{RT-qPCR}

Extraction of RNA from the proximal, middle, and distal small intestine, cecum, and proximal, middle, and distal colon samples was performed as described previously. ${ }^{23}$ cDNA was synthesized using a QuantiTect Reverse Transcription Kit (Qiagen, Hilden, Germany), according to the manufacturer's protocol. Quantitative RT-PCR (RT-qPCR) was performed using QuantiTect Primer Assays for Zo-1 (Mm_Tjp1_1_SG; Qiagen), claudin-4 (Mm_Cldn4_1_SG), claudin-2 (Mm_Cldn2_2_SG), occludin (Mm_Ocln_1_SG), and Cd14 (Mm_CD14_SG), as well as TaqMan Gene Expression Assays for Tnf $\alpha$ (Mm00443258_m1), Ifn $\gamma$ (Mm01168134_m1), and Mlck1 (Mm00653039_m1). Actin (Mm_Actb_2_SG, Mm00607939_s1) was used as an endogenous control. Gene expression was detected with a StepOnePlus Real-Time PCR System (Applied Biosystems, Weiterstadt, Germany) using Fast SYBR Green Master Mix and TaqMan Fast Advanced Master Mix, according to the manufacturer's instructions. All reactions were run in triplicate. The amplified PCR products were verified by melting curve analysis. Relative gene expression was calculated using the $2^{-\Delta \Delta \mathrm{Ct}}$ method or was determined relative to a reference sample.

\section{Flow Cytometry}

Cells analyzed by flow cytometry were isolated from the colon. For flow cytometry staining, cell numbers were adjusted to $1 \times 10^{6}$ cells/well. Cells were stained with anti-CD45-PerCPCy5.5 (Biolegend, San Diego, CA), CD326-APC_V770, B220-VB (both Miltenyi Biotec, Bergisch Gladbach, Germany), CD90.2-APC-Cy7, F4/80-APCCy7, CD11b-BV-421, CD11c-fluorescein isothiocyanate (FITC), Ly6G-PerCP-Cy5.5, and CD14-PE (all from Biolegend, San Diego, CA). Cells were analyzed in the Gallious
Flow Cytometer (Beckman Coulter, Brea, CA), and histograms were plotted using KaluzaFlow Cytometry Analysis software version 1.3 (Beckman Coulter).

\section{Histology}

The samples were fixed in $4 \%$ neutral buffered formalin, processed routinely, embedded in paraffin, divided into sections (5 to $6 \mu \mathrm{m}$ thick), and stained with hematoxylin and eosin. Histology slides were scored based on previously described colitis scores, with the separate grading of histopathological lesions in the proximal, middle, and distal colon. $^{7,24,25}$

\section{Immunofluorescence}

For immunofluorescence staining of the formalin-fixed, paraffin-embedded tissue sections, a rabbit anti-occludin polyclonal primary antibody (Invitrogen, Darmstadt, Germany) or a rabbit anti-Ki-67 antibody (Abcam, Cambridge, UK) and a DyLight 594 conjugated donkey antirabbit polyclonal secondary antibody (Abcam) were used. Nuclear counterstaining was performed with a mounting medium containing DAPI (Vectashield; Vector Laboratories, Burlingame, CA) and was examined using a Zeiss Axioskop 40 microscope (Carl Zeiss Microscopy GmbH, Göttingen, Germany). The proliferation rate was determined by two independent examiners by counting the number of $\mathrm{Ki}$ 67 -positive cells in the lamina propria per visual field (10 fields per slide). The immunofluorescence staining of tissue sections for NF- $\kappa$ B-p65 was performed using a TSA Cy3 system as recommended by the manufacturer (PerkinElmer, Waltham, MA). An NF- $\kappa$ B p65 (D14E12) XP rabbit monoclonal antibody (Cell Signaling Technology, Danvers, MA) was used as a primary antibody. Nuclei were counterstained with Hoechst 3342 (Invitrogen). Images were obtained using a LEICA DMI 4000B microscope together with a LEICA DFC360 FX camera and LAS AF imaging software version 2.7.0.9329 (Leica, Wetzlar, Germany).

\section{Cell Death}

The percentage of intestinal cells undergoing cell death was quantified by terminal deoxynucleotidyl transferasemediated dUTP nick-end labeling (TUNEL) staining (In situ Cell Death Detection Kit, TMR red; Roche, Basel, Switzerland), according to the manufacturer's protocol. DAPI staining was performed to visualize nuclei. Samples were prepared in duplicate. The cell death rate was determined by two independent examiners by counting the number of apoptotic cells per visual field (10 fields per slide).

\section{Electrophysiological and Flux Measurements}

Measurements were performed in miniaturized Ussing chambers, as described previously. ${ }^{26,27}$ Briefly, four distal 
small intestine/ileum samples of approximately $1 \mathrm{~cm}$ in length were removed sequentially, immediately rinsed with ice-cold saline, and kept in a modified Krebs-Henseleit buffer solution that was continuously gassed with carbogen. Intestinal tissues were placed into Ussing chambers, and the experiments were performed under short-circuit current conditions using a computer-controlled voltageclamp device that continuously monitored the short-circuit current $\left(I_{\mathrm{sc}} ; \mu \mathrm{mol} \cdot \mathrm{h}^{-1} \cdot \mathrm{cm}^{-2}\right)$ and tissue conductance $\left(\mathrm{G}_{\mathrm{t}} ; \mathrm{mS} \cdot \mathrm{cm}^{-2}\right)$. Paracellular permeability was determined under short-circuit conditions, as described previously. ${ }^{28}$ For determination of unidirectional flux rates, $4.0 \mu \mathrm{Ci}$ $\left[{ }^{3} \mathrm{H}\right]$-mannitol was added to the mucosal side of the chamber at the end of an equilibrium period. Transport rates were calculated according to standard equations. ${ }^{29}$ The mean flux rates for four 15-minute intervals were used to estimate the basal paracellular permeability.

\section{ELISA}

Six hours after initiation of the culturing of CMT93 cells treated with LPS and CD14, the medium was collected and analyzed by enzyme-linked immunosorbent assay (ELISA) following the instruction guide of Biolegend (ELISA MAX Deluxe Set for mouse IL-6). OD was measured using an ELISA Reader (VictorX3; PerkinElmer, Waltham, MA). Quantikine mouse CD14 ELISA (R\&D Systems, Minneapolis, MN) was used to analyze $\mathrm{CD} 14$ expression in different parts of the intestines of $\mathrm{C} 3 \mathrm{H} / \mathrm{HeJ}, \mathrm{C} 3-1 / 10^{-/-}$, B6-wt, and B6-Illo ${ }^{-/-}$mice, including the proximal, middle, and distal parts of the small intestine, the cecum, and the proximal, middle, and distal parts of the colon. Before performing ELISA, cytosolic proteins were isolated from the intestinal tissues and quantified using the Bradford method. The CD14 levels were then measured in samples diluted 50-fold according to the manufacturer's instructions. Absorbance was measured at $450 \mathrm{~nm}$ with an ELISA Reader (VictorX3). The CD14 concentration was then calculated relative to the amount of protein per sample.

\section{Metabolic Cages}

For in vivo measurement of intestinal permeability, the fluorescence intensity of orally administered FITC-dextran was measured in the urine. The food and water supplies of the mice were withdrawn at 4 hours before initiation of the experiment. FITC-dextran (4 kDa; Sigma Aldrich) at a concentration of $0.6 \mathrm{mg} / \mathrm{g}$ body weight was administered by oral gavage, and the mice were housed individually in metabolic cages for an additional 4 hours. Next, urine samples were collected and diluted in $0.5 \mathrm{~mol} / \mathrm{L}$ HEPES

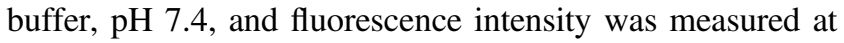
$490 / 535 \mathrm{~nm}$ using a Victor X3. The total amount of FITC-dextran uptake was calculated according to the volume of excreted urine.

\section{Statistical Analysis}

All analyses were performed in a randomized and blinded manner. If not stated otherwise, the values are presented as the means \pm SEM. All statistical analyses were performed using GraphPad Prism software version 6 (GraphPad Software, La Jolla, CA). For parametric data, $t$-tests (with Welsh correction, if necessary, ie, when variances were significantly different) and one-way analysis of variance were performed, using Tukey's test or the Newman-Keuls test as a post hoc test. For nonparametric data (histological scores), the Mann-Whitney test and Kruskal-Wallis test, as well as post hoc Dunn's test, were performed. For analysis of body weight loss over time, two-way analysis of variance was performed, using the Sidak test as a post hoc test. $P<0.05$ was considered significant.

\section{Results}

CD14 Prevents the Increase in Barrier Permeability after LPS Stimulation in CMT93 Cells and Leads to NF- $\kappa B$ Activation

CMT93 cells have been shown to be Cd14-deficient; therefore, this cell line was used to analyze the role of CD14 in barrier permeability regulation. ${ }^{30}$ Cells were cultured for approximately 4 days and were then treated with LPS, CD14, or both LPS and CD14 (Figure 1A). LPS has been previously shown to increase cell barrier permeability. ${ }^{31}$ Consistent with this finding, LPS caused a significant decrease in TEER. In contrast, stimulation with CD14 did not change barrier integrity. Treatment of CMT93 cells with both LPS and CD14 resulted in enhanced barrier function compared to LPS treatment alone, although a lower TEER was observed compared to that resulting from CD14 treatment alone. Furthermore, IL-6 secretion was measured in the supernatants of LPS- and CD14-treated cells and was found to be increased in a CD14 dose-dependent manner (Figure 1B). As CD14 binds circulating LPS and leads to TLR4-mediated $\mathrm{NF}-\kappa \mathrm{B}$ activation, ${ }^{12}$ this pathway is likely to be involved in the underlying mechanism of barrier regulation. For quantification of the NF- $\mathrm{KB}$ signaling, the CMT93 cells were again treated with LPS, CD14, and both LPS and CD14 for half an hour followed by Western blot analysis of phospho-NF- $\mathrm{BB}-$ p65 (Figure 1C). The phospho-NF- $\kappa$ B-p65 expression was not up-regulated in cells treated with LPS or CD14 alone but was found to be significantly increased after stimulation with both. These data suggest that CD14 plays pivotal roles in barrier permeability and $\mathrm{TJ}$ regulation and sensitizes for LPS-mediated NF- $\kappa \mathrm{B}$ activation.

\section{Cd14 Expression Is Mouse Strain and Gut Location Dependent}

To examine CD14 expression along the gut of C3 and B6 mice, the small intestine, cecum, and colon were sampled from the respective mouse strains. The small intestine and colon 

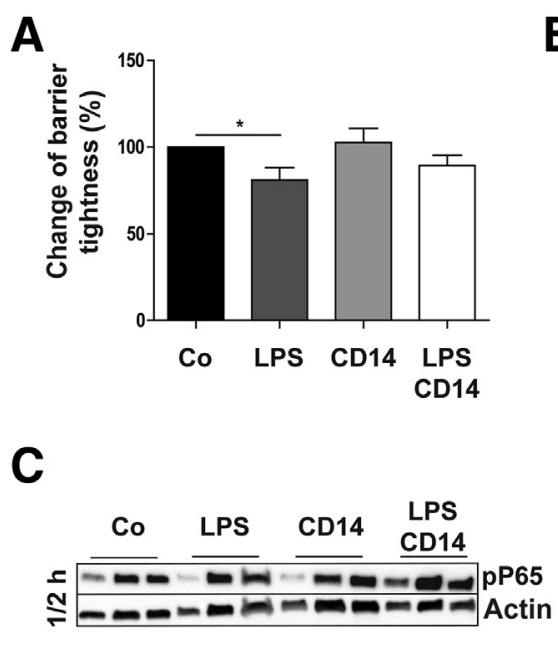

B
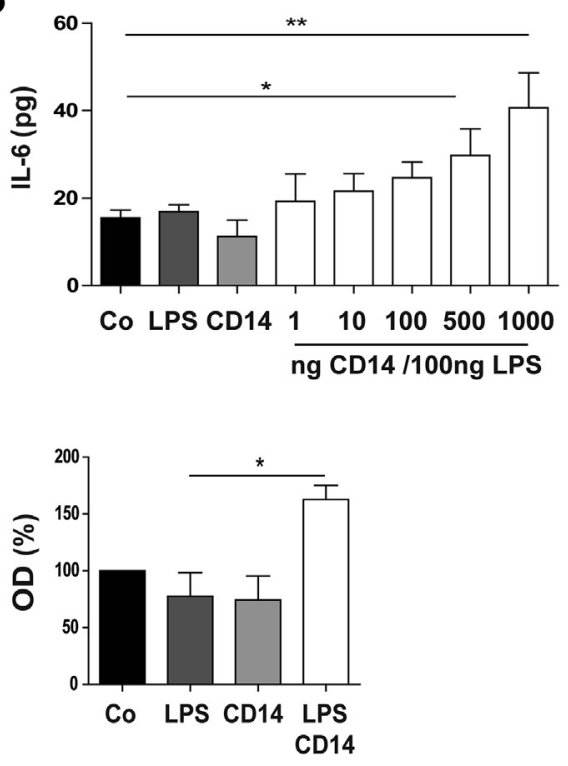

Figure 1 Barrier integrity of CMT93 cells. The colon epithelial cell line CMT93 was cultured in transwell plates. A: After administration of both $100 \mathrm{ng} / \mathrm{mL}$ LPS and $1000 \mathrm{ng} / \mathrm{mL}$ CD14 or LPS or CD14 alone, barrier integrity was evaluated by measuring TEER. B: CD14-dependent IL-6 production during LPS stimulation. C: Detection of phospho-NF- $\kappa$ B-p65 (pP65) by Western blot analysis of lysates from CMT93 cells. Three biological replicates per group were analyzed. Densitometric quantification normalized to actin was calculated as change from the control group (Co). Data are expressed as means \pm SEM $(\mathbf{A}-\mathbf{C}) . n=3(\mathbf{A}-\mathbf{C})$. ${ }^{*} P<0.05,{ }^{*} P P<0.01$ (one-way analysis of variance). were fragmented into three units: distal, middle, and proximal. Cd14 expression was higher in various analyzed regions of the C3 mice compared to the B6 mice, as determined by RT-qPCR. The highest levels of Cd14 expression were detected in the colon, whereas it was expressed at low levels in the small intestine and cecum. C3-IllO ${ }^{-/-}$mice exhibited the highest Cd14 mRNA in the cecum. B6-Illo ${ }^{-1-}$ mice showed similar expression throughout the whole intestine with low levels in the proximal and middle part of the small intestine and the middle colon (Figure 2A). In addition, CD14 protein expression was elevated in the $\mathrm{C} 3$ and $\mathrm{C} 3-1 / 10^{-/-}$mice compared to the $\mathrm{B} 6$ and $\mathrm{B} 6-1110^{-1-}$ mice in most areas of the gut (Figure 2B). CD14 protein expression was not detected in the analyzed regions of the distal small intestines or proximal colons of the B6 mice or in the middle or distal small intestines of the B6-Illo ${ }^{-1-}$ mice. Although mRNA and protein expression was not totally matching, CD14 seems to be most present in the large intestine. Thus, Cd14 expression appeared to be mouse strain dependent, with differential expression in various areas of the small intestine and colon, demonstrating the diversity of its expression. We previously showed that difference in the $\mathrm{CD} 14$ expression between $\mathrm{C} 3$ and $\mathrm{B} 6$ mice was because of a higher secretion of sCD14 in $\mathrm{C} 3$ mice. ${ }^{9}$ To further characterize CD14-expressing cells in the mouse gut, various cell types of the colon of $\mathrm{B} 6-\mathrm{IlIO}^{-/-}$mice were analyzed using flow cytometry. A slight CD14 expression was found in almost all analyzed cells, such as immune cells, including B cells, T cells, macrophages, dendritic cells, and granulocytes, as well as epithelial cells (CD326 ${ }^{+}$) (Figure 2C).

\section{Intestinal Barrier Integrity Is Not Diminished in $\mathrm{Cd}_{14^{-}}{ }^{-}$Mice under Steady-State Conditions}

For determination of intestinal barrier integrity, FITCdextran was administered orally, and fluorescence was measured in the urine after 4 hours. No differences in intestinal barrier integrity were observed between the wild-type and $\mathrm{Cd}_{14^{-1-}}$ mice (Figure $3 \mathrm{~A}$ ). In addition, no differences were detected in Ussing chamber analyses performed to assess the ileal and colonic epithelia of the wt and $\mathrm{Cd}_{14^{-/}}$mice (Figure 3B). Consistent with these findings, no bacterial translocation into the spleen, liver, or mesenteric lymph nodes was detected in the $\mathrm{Cd} 14^{-/-}$mice (data not shown), further indicating that the barrier was functional under steady-state conditions. Furthermore, no inflammation was detected histologically in the colons of these mice (Figure 3C). The expression of TJ proteins, such as Zo-1, occludin, claudin-4, and claudin-2, did not vary between the wt and $\mathrm{Cd} 14^{-/}$mice (Figure 3D). In addition, proliferation, as measured by $\mathrm{Ki}-67$ staining, and cell death, as measured by TUNEL assay, did not differ in lamina propria cells between the $C d 14^{--}$and wt mice (Figure 3E).

\section{Germ-Free Monoassociated $\mathrm{Cd} 14^{-/-}$Mice Possess an Intestinal Barrier Disturbance}

B6 wt and $C d 14^{-/-}$mice were housed under germ-free conditions. Oral application of $E c N$ to these mice resulted in invasion from the gut to the spleen in the $C d 14^{-/-}$mice, but not in the wt mice (Figure 4A). EcN monocolonization led to a detectable up-regulation of Zo-1 mRNA expression in B6 wt mice but not in $\mathrm{Cd} 14^{-/-}$mice, as well as significant down-regulation of occludin expression. Claudin-4 and claudin-2 expression was comparable between wt and $\mathrm{Cd}_{14^{-/}}$mice (Figure 4B). Furthermore, cell death and proliferation rate of intestinal cells in the ileum were found to be slightly increased after $E c N$ monoassociation, but no significant differences were detected between wt and Cd14-deficient mice (Figure 4C). Thus, barrier integrity 

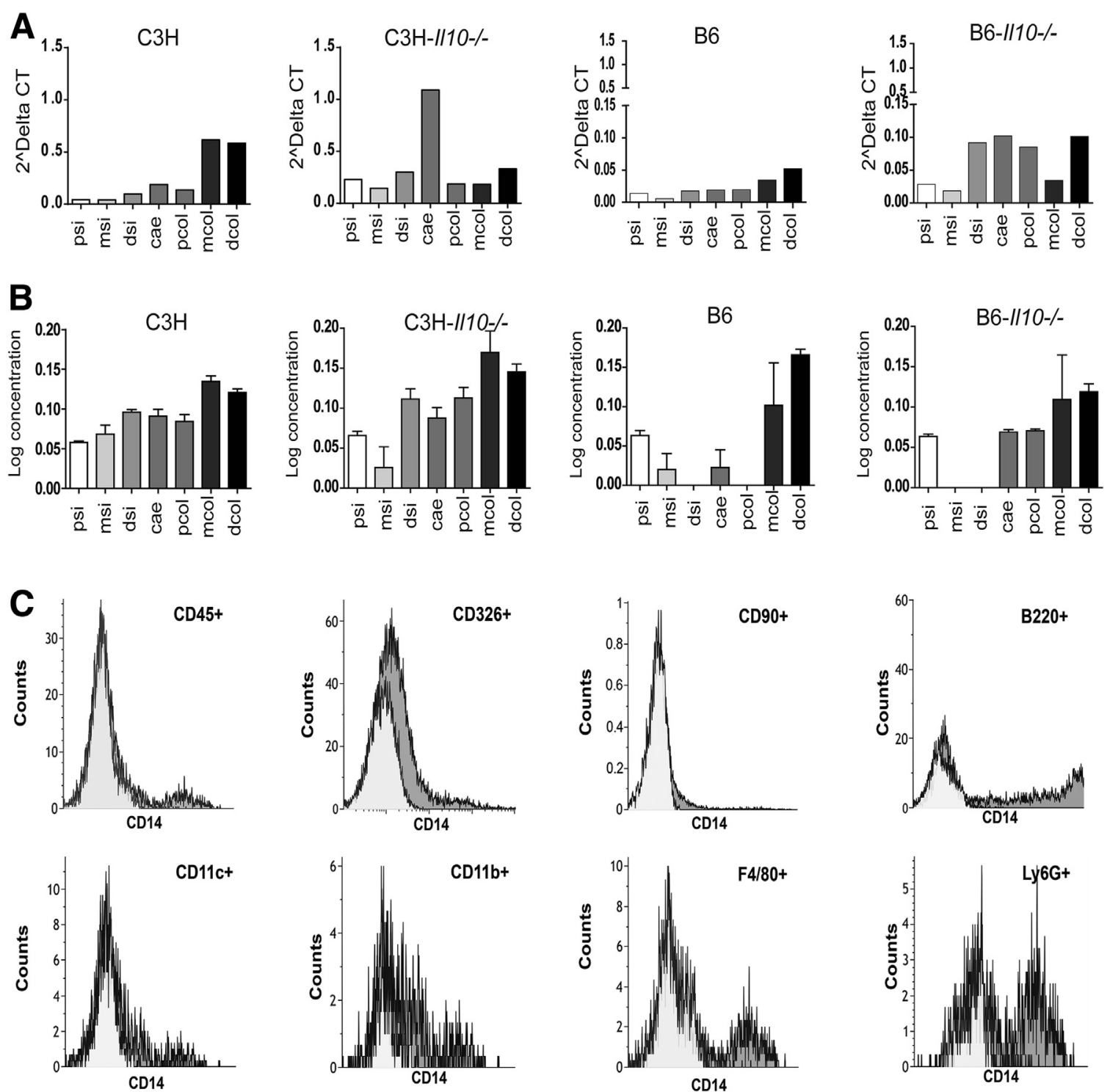

Figure 2 Differential expression pattern of $C d 14$ along the intestine. Quantitative RT-PCR and ELISA were performed on small intestine, cecum (cae), and

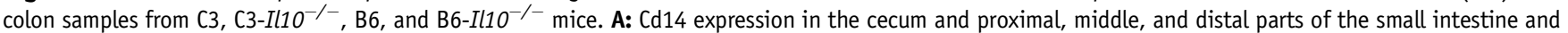
colon. Three animals per group were pooled and analyzed, and relative differences in gene expression were calculated using the comparative $2^{-\Delta \Delta C t}$ method. B: CD14 protein expression was detected by ELISA in various intestinal and colonic regions. C: CD14 was measured in the colonic cell suspension of B6-Il10 ${ }^{-1-}$ mice using flow cytometry. Representative histograms of different immune cells and epithelial cells (CD45 $\left.{ }^{-} \mathrm{CD} 326^{+}\right)$were presented (four independent experiments). Data are expressed as means \pm SEM (A and $\mathbf{B}) . n=3$ (B); $n=3$ to 9 (C). dcol, distal colon; dsi, distal small intestine; mcol, middle colon; msi, middle small intestine; pcol, proximal colon; psi, proximal small intestine.

appeared to be disturbed in the $C d 14^{-/-}$mice in association with bacterial colonization.

\section{Cd14 ${ }^{-/-}$Mice Display an Impaired Intestinal Barrier under Acute and Chronic Inflammatory Conditions}

Barrier permeability was examined in the presence of acute and chronic inflammation. After the DSS treatment, $\mathrm{Cd} 14^{-/-}$mice lost weight, in contrast to the wt mice (Figure 5A), and had more severe inflammatory lesions in the colon (Figure 5B). RT-qPCR analysis of colonic tissues revealed that Ifn- $\gamma$ expression was increased in the $C d 14^{-/-}$mice compared to that in the wt mice after the
DSS treatment (Figure 5C). No Ifn- $\gamma$ expression was detected under steady-state conditions in either of the analyzed mouse strains. Tnf- $\alpha$ expression was increased in all of the DSS-treated mice, but no difference was detected between the $C d 14^{-1-}$ and wt mice. Furthermore, the FITCdextran level was higher in the DSS-treated $\mathrm{Cd}_{14^{-/-}}$mice (Figure 5D). Occludin as well as claudin-2 expression was slightly decreased during acute colitis in the $\mathrm{Cd}_{14^{-/-}}$mice compared to the wt mice, whereas Zo-1 and claudin-4 showed no differences (Figure 5E). Furthermore, detected occludin reduction was confirmed by immunohistology, as depicted in Figure 5E. The numbers of TUNEL-positive cells and proliferating cells were 


\section{A}

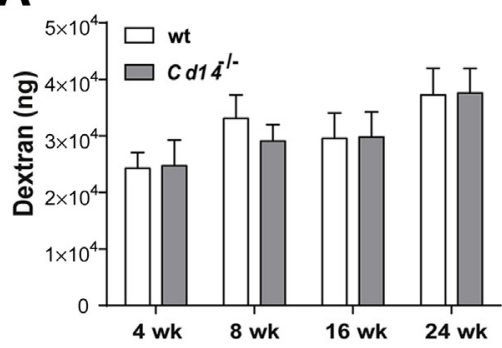

B
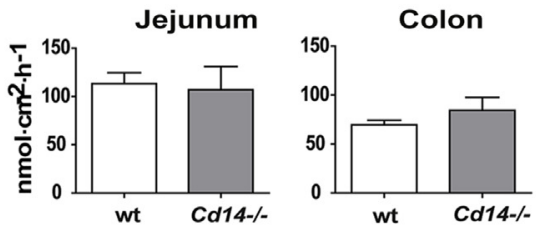

C
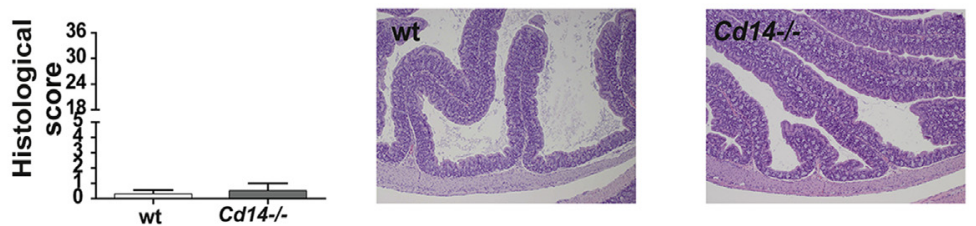

D
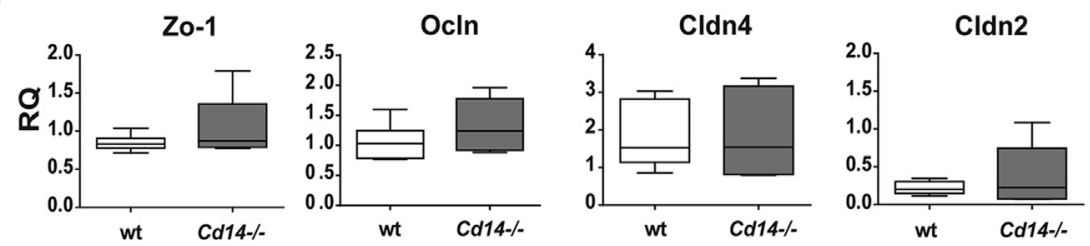

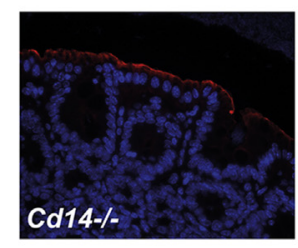

Figure 3 Intestinal barrier permeability in $\mathrm{Cd}_{14^{-/-}}$mice. A: FITC-dextran uptake in vivo was measured in urine samples collected from wildtype (wt) and $\mathrm{Cd}_{14}{ }^{-/-}$mice maintained in metabolic cages. The mice were analyzed from 4 to 24 weeks after birth. B: Mannitol flux ex vivo was measured in the jejuna and colons of wt and Cd14 $4^{-/}$mice using Ussing chambers. C: Histological scores were determined to quantify the alterations observed in the colons. D: Quantitative RT-PCR analysis of zonula occludens protein-1 (Zo-1), occludin (0cln), claudin-4 (Cldn4), and claudin-2 (Cldn2) expression in cecum samples. Relative differences in gene expression were calculated using a reference sample. The values are presented as fold changes. Immunofluorescence staining for occludin (red) in cecum tissues from wt and $C d 14^{-/}$mice. Nuclei (blue) were counterstained with DAPI. E: Quantification of TUNELpositive cells and Ki-67-positive cells per optical view in cecum samples from wt and $\mathrm{Cd}_{14^{-}}{ }^{-}$mice. Data are expressed as means \pm SEM $(\mathbf{A}-\mathbf{C}$ and $\mathbf{E})$ or as median and minimum to maximum (D). $n=7$ to 9 (A and $\mathbf{E}) ; n=6$ to 7 (B); $n=7$ to 8 (C); $n=6$ to 8 (D). Original magnification: $\times 5$ (C); $\times 40$ (D).

\section{E}
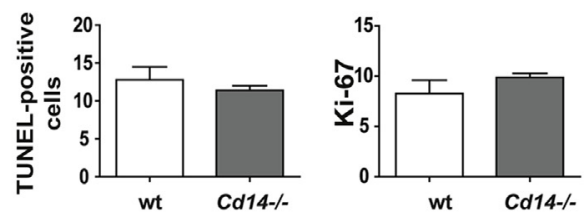

significantly increased in the $C d 14^{-1-}$ mice compared to the wt mice (Figure 5F). Thus, the intestinal barrier was less effective in the $C d 14^{-/-}$mice after induction of acute inflammation.

In the $I l 10$ deficiency model of chronic colitis, $I l 10^{-1-}$ $\mathrm{Cd} 14^{-1-}$ mice developed more severe chronic colitis than the $1110^{-1-}$ mice (Figure 6A). Furthermore, Tnf- $\alpha$ and Ifn- $\gamma$ expression were increased in the $1110^{-1-} \mathrm{Cd}_{14^{-1-}}$ mice compared to the Ill0-deficient controls (Figure 6B). Consistent with these findings, the $1110^{-1-} \mathrm{Cd} 14^{-1-}$ mice exhibited stronger fluorescent signals in the urine after FITC-dextran administration compared to the $1110^{-1-}$ control mice, detected as early as 8 weeks of age (Figure $6 \mathrm{C}$ ). Furthermore, the levels of the TJ proteins claudin-4, claudin-2, and occludin were decreased, as determined by both RT-qPCR and immunohistology (Figure 6D).
TUNEL-positive cells were increased in the $1110^{-1-}$ $C d 14^{-/-}$mice compared to the 1110 -deficient mice, whereas lamina propria cell proliferation was slightly reduced (Figure 6E). Thus, CD14 seems to play a pivotal role in the maintenance of barrier integrity in the colitis models. The presence of CD14 appears to be more important when the epithelial layer is disturbed; after LPS stimulation or epithelial breakdown or damage, it seems to be essential for reestablishing homeostasis.

\section{CD14 0verexpression Is Protective in Acute, DSS-Induced Colitis}

A protective effect of CD14 was detected in transgenic mice (M14S), in which its expression was up-regulated in different cell types, including intestinal cells, after zinc administration 

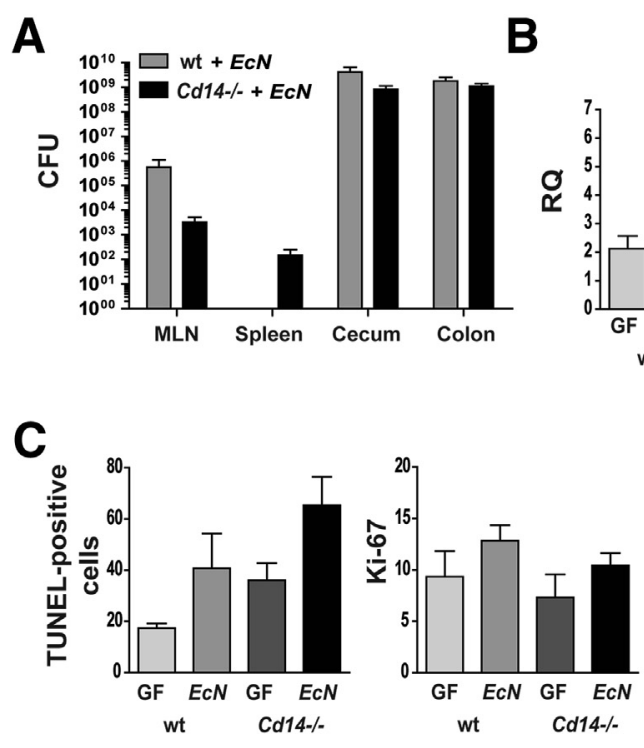
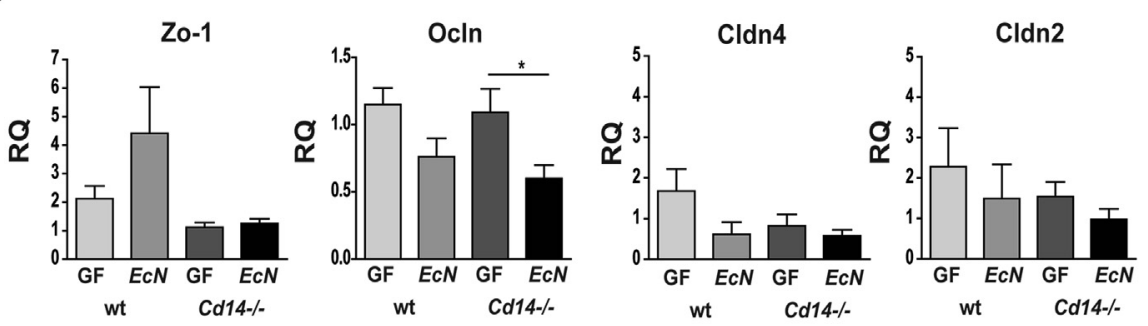

Figure 4 Epithelial barrier impairment in Escherichia coli Nissle $(E C N)$ monoassociated Cd14 ${ }^{-/}$mice. A: Colony-forming units (CFUs) were measured after 72 hours after infection in the cecum and colon contents, mesenteric lymph nodes (MLNs), and spleen. B: Expression of zonula occludens protein-1 (Zo-1), occludin (Ocln), claudin-4 (Cldn4), and claudin-2 (Cldn2) were measured by quantitative RT-PCR using total RNA isolated from distal small intestine tissue homogenates. Relative differences in gene expression were calculated using a reference sample. The values are presented as fold changes. C: Quantification of TUNEL-positive cells and Ki67-positive cells per optical view in small intestine samples from untreated and $E$. coli Nissle monoassociated wild-type (wt) and $\mathrm{Cd}_{14^{-/-}}$mice. Data are expressed as means \pm SEM. $n=7$ to $8(\mathbf{A}) ; n=5$ to 8 (B); $n=6$ to 8 (C). ${ }^{*} P<0.05$ (one-way analysis of variance). GF, germ-free.

(Supplemental Figure S1). ${ }^{21}$ Although similar amounts of weight loss were observed after DSS treatment between the M14S-CD14 ${ }^{\text {high }}$ mice and M14S controls (M14S-CD14) (Figure 7A), the M14S-CD14 ${ }^{\text {high }}$ mice, in which CD14 was overexpressed, exhibited less inflammation in the colon than the M14S controls (Figure 7B). Analysis of proinflammatory cytokine expression revealed that Tnf- $\alpha$ expression was significantly lower in the DSS-treated M14S-CD14 ${ }^{\text {high }}$ mice than in the controls (Figure 7C). No Ifn- $\gamma$ expression was detected in either DSS-treated group. Furthermore, the FITCdextran level was decreased in the M14S-CD14 ${ }^{\text {high }}$ mice (Figure 7D) in parallel with increased expression of TJ proteins, such as occludin, claudin-4, and claudin-2 (Figure 7E). Cell death as well as proliferation showed no differences (Figure 7F). However, the zinc-treated wt mice were not protected from inflammation (Supplemental Figure S2). Taken together, our results have demonstrated a protective influence of CD14 on the development of experimental colitis. CD14 seems to tighten the epithelial intestinal barrier and to decrease proinflammatory cytokine expression.

\section{Intestinal Epithelial NF- $\kappa$ B Activation Seems Not to Be Involved in the CD14-Dependent Barrier Regulation}

To determine whether the influence of CD14 on barrier function is because of altered epithelial NF- $\kappa \mathrm{B}$ activation, immunohistological staining was performed for NF- $\mathrm{KB}-\mathrm{p} 65$ in the intestine (Figure 8). As expected, stronger nuclear fluorescent signals were observed in lamina propria cells of all mice during acute and chronic inflammation compared to the untreated $\mathrm{Cd}_{14^{-/-}}$and wt mice. These cells are most likely representing infiltrating immune cells. However, only a slight nuclear NF- $\mathrm{B}-\mathrm{p} 65$ signal could be detected in the epithelial cells of all investigated groups. Most important, no differences were observed between the $C d 14^{-/-}$and wt mice, independent of intestinal inflammation. Furthermore, the
CD14-overexpressing mice also did not differ from controls in epithelial NF-кB-p65 activation. Therefore, altered epithelial $\mathrm{NF}-\kappa \mathrm{B}$ signaling does not seem to be responsible for the less effective barrier function in Cd14-deficient animals or the barrier improvement of the CD14-overexpressing mice.

\section{TNF- $\alpha$ Does Not Up-Regulate Mlck Expression}

Because both TNF- $\alpha$ and IFN- $\gamma$ are able to alter the intestinal permeability, ${ }^{32-34} \mathrm{CD} 14$ could indirectly influence the intestinal barrier function by modifying the intestinal inflammation process. As it is known that TNF- $\alpha$ can alter the intestinal TJ barrier by up-regulation of epithelial expression of myosin light chain kinase (Mlck), ${ }^{35}$ the Mlck expression was analyzed in the colon by RT-qPCR. Surprisingly, Mlck expression was found to be significantly decreased in the Cd14-deficient mice compared to wt controls under steady-state conditions, although no difference in intestinal Tnf- $\alpha$ expression could be detected (Figure 9A). Decreased Mlck expression was also observed in germ-free Cd14 ${ }^{-1-}$ mice compared to wt controls (Figure 9B) as well as in $\mathrm{Cd} 14^{-1-} \mathrm{Ill0^{-/- }}$ mice compared to $I l 10^{-1-}$ controls (Figure 9D). However, after $E c N$ monoassociation and also under DSS treatment, no difference could be observed between the groups independent of CD14 (Figure 9, B, C, and E). As the Mlck expression should increase together with the intestinal permeability, the TNF- $\alpha$-induced Mlck expression is not likely to be involved in the underlying mechanism of CD14-dependent barrier regulation.

\section{Discussion}

Induction of intestinal epithelial barrier disruption is considered a potential trigger for IBD development; however, the influencing factors, as well as the mechanisms regulating barrier integrity, are not well understood. Both 
A

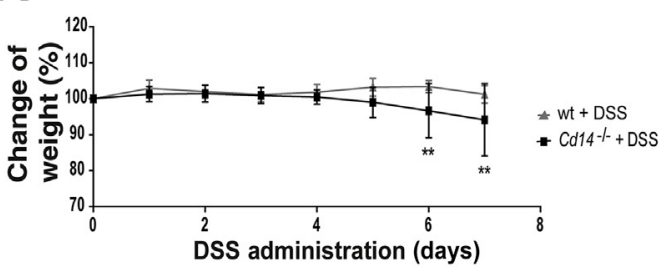

C

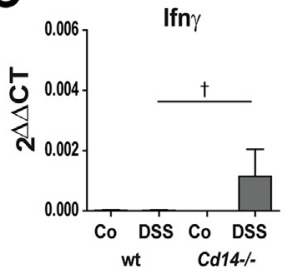

$\mathbf{E}$
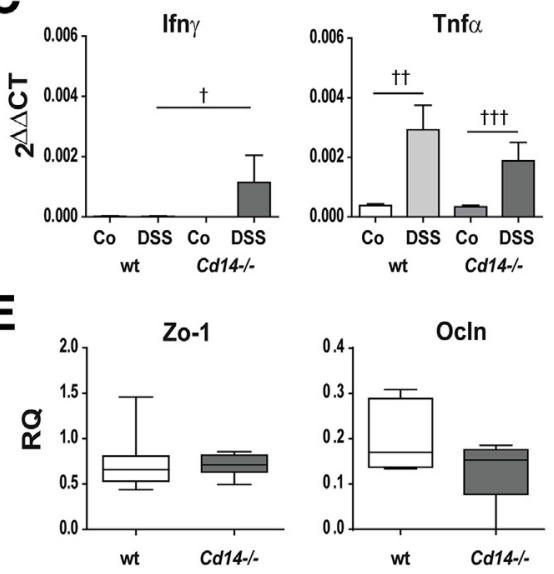
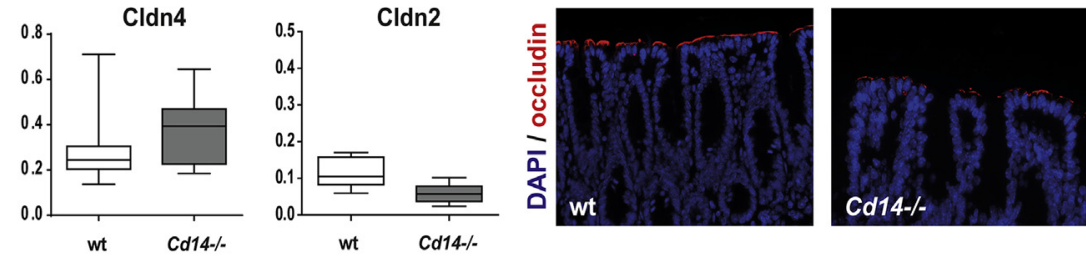

$\mathbf{F}$
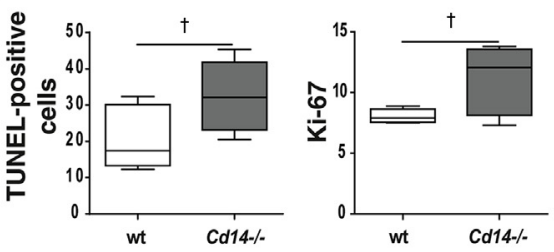

Figure 5 Intestinal barrier disruption during acute inflammation in $\mathrm{Cd}_{14^{-/}}$mice. All mice were treated with $1 \%$ DSS for 7 days. A: Body weight was measured over time and calculated as the change from the initial body weight. Significant differences detected by two-way analysis of variance are indicated. B: Histological scores were determined to quantify the alterations observed in the colons. Significant differences detected using the Mann-Whitney test are indicated. C: The expression of proinflammatory cytokines, such as interferon (Ifn)- $\gamma$ and tumor necrosis factor (Tnf)- $\alpha$, was detected via quantitative RT-PCR (RT-qPCR) in colons from untreated and DSS-treated wild-type (wt) and $C d 14^{-/-}$mice. Relative differences in gene expression were calculated using the comparative $2^{-\Delta \Delta C t}$ method. Significant differences detected using the Mann-Whitney test are indicated. D: FITC-dextran uptake was measured in urine samples collected from DSS-treated wt and $\mathrm{Cd}_{1} 4^{-/-}$mice maintained in metabolic cages. Significant differences detected using the unpaired $t$-test are indicated. E: RT-qPCR analysis of zonula occludens protein-1 (Zo-1), occludin (0cln), claudin-4 (Cldn4), and claudin-2 (Cldn2) expression in cecum samples. Relative differences in gene expression were calculated using a reference sample. The values are presented as fold changes. Immunofluorescence staining for occludin (red) in cecum tissues from wt and $\mathrm{Cd}_{1} 4^{-/-}$mice. Nuclei (blue) were counterstained with DAPI. F: Quantification of TUNEL-positive cells and Ki$67-$ positive cells per optical view in cecum samples from wt and $C d 14^{-/-}$mice. Significant differences detected using the unpaired $t$-test. Data are expressed as means \pm SEM $(\mathbf{A}$ and $\mathbf{C}$ ) or as median and minimum to maximum (B and $\mathbf{D}-\mathbf{F}) . n=8(\mathbf{A}) ; n=11$ to $13(\mathbf{B}) ; n=6$ to $7(\mathbf{C}$ and $\mathbf{E}) ; n=5(\mathbf{D}$ and $\mathbf{F})$. ${ }^{\star} P<0.05$ versus control; ${ }^{\dagger} P<0.05,{ }^{\dagger \dagger} P<0.01$, and ${ }^{\dagger \dagger \dagger} P<0.001$. Original magnifications: $\times 5$ (B); $\times 40$ (E).

environmental stimuli and genetic factors are involved in maintaining barrier integrity. ${ }^{1}$ Therefore, this study aimed to elucidate the influence of CD14 on intestinal mucosal integrity under steady-state conditions and in the presence of acute and chronic inflammation. $C d 14$ has been previously demonstrated to be a candidate gene mediating colitis susceptibility in the Ill0-deficiency-induced mouse model of IBD. ${ }^{7}$

To investigate the role of CD14 in barrier integrity, we first analyzed $\mathrm{Cd} 14$ expression in four different mouse strains and in different parts of the intestinal tract. It was found to be differently expressed between $\mathrm{C} 3$ and $\mathrm{B} 6$ mice, as well as between $\mathrm{C} 3-1 / 10^{-/-}$and $\mathrm{B} 6-1110^{-/-}$mice.
Increased $\mathrm{Cd} 14$ expression was detected in the $\mathrm{C} 3$ mice compared to the B6 mice. This strain-dependent difference in Cd14 expression in the intestine is dependent on microbiota colonization, as we have previously shown that its expression is decreased in both mouse strains under germfree conditions. ${ }^{7}$ Similar to our results, Ortega-Cava et $\mathrm{al}^{36}$ reported that $\mathrm{Cd} 14$ expression was the highest in the distal colon of BALB/c mice and that it was increased after DSS treatment. The increased expression at this location is correlated with the distribution of microorganisms in the gastrointestinal tract, as the highest numbers of bacteria are present in the distal colon. ${ }^{37,38}$ Consistent with this, we found the highest CD14 concentrations in the distal parts of 
A

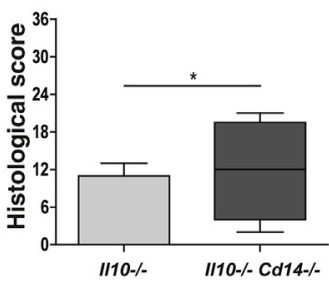

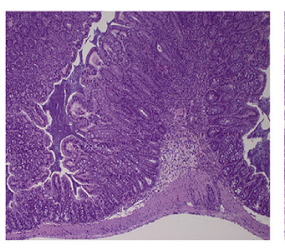

II10-

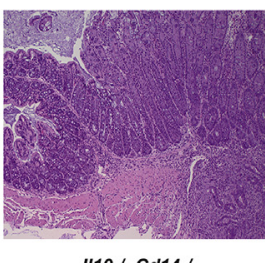

II10-/ Cd14-\%

C

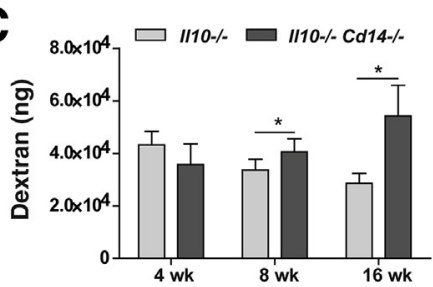

B
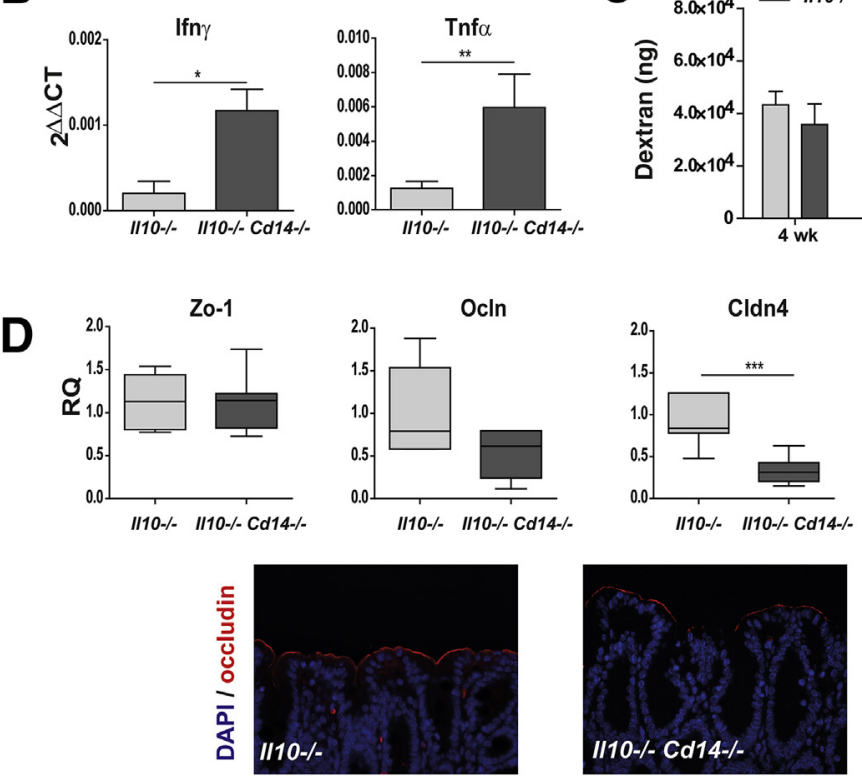

\section{E}
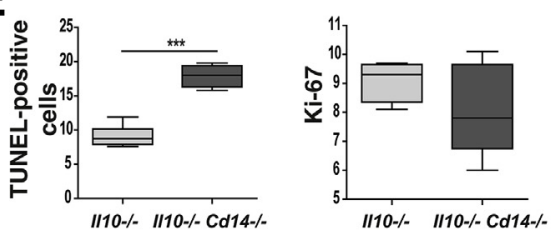

the large intestine and in the cecum. Furthermore, Cd14 has been shown to be differentially expressed in the kidneys of various mouse strains after unilateral ureteral obstruction, ${ }^{39}$ whereas no differential expression has been detected in the liver or serum. ${ }^{9}$ Cd14 expression seems to be differentially regulated depending on the organ location and mouse strain and to also be dependent on microbiota colonization. As an important TLR4 coreceptor, CD14 binds circulating LPS. CD14 exists either as a membrane-bound receptor on the cell surface or is secreted as a soluble form (sCd14) transferring the LPS to cells lacking the membrane-bound form. ${ }^{40}$ We previously showed higher secretion of sCD14 in $\mathrm{C} 3$ mice compared to B6 animals, whereas membranebound CD14 expression did not differ between the mouse strains. ${ }^{9}$ To further analyze CD14-expressing cells in the gut, we analyzed different cell types by flow cytometry. CD14 expression was detected in both immune cells and epithelial cells. Consistent with this, Hornef et $\mathrm{al}^{41}$ showed that epithelial cells express CD14, which was up-regulated

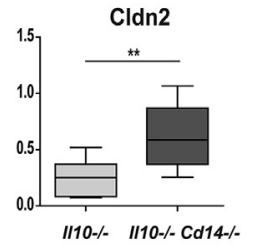

after LPS exposure. Thus, CD14 seems to be widely expressed among cell types and could possibly play an important role in maintaining intestinal homeostasis.

CMT93 cells, derived from a rectum epithelial mouse cell line, were previously shown to be CD14 deficient. ${ }^{30}$ Using these cells for TEER experiments, a decrease in barrier tightness was measured after LPS treatment. This is consistent with others who also measured a decrease in TEER in colonic or intestinal epithelial cell lines, such as Caco-2, NCM460, and T84 cells, after LPS treatment. ${ }^{31}$ As CMT93 cells were shown to be CD14 deficient, recombinant CD14 was administered in addition to LPS stimulation to analyze the effect of sCD14 on barrier integrity. Although there was a decrease in barrier tightness, the effect was only moderate compared to LPS treatment alone. Therefore, sCD14 seems to improve the cell barrier integrity during LPS treatment. sCD14, as a coreceptor of various TLRs, recognizes and binds LPS. By binding together with lipopolysachharidbinding-protein, epithelial and endothelial cells are activated. 
A

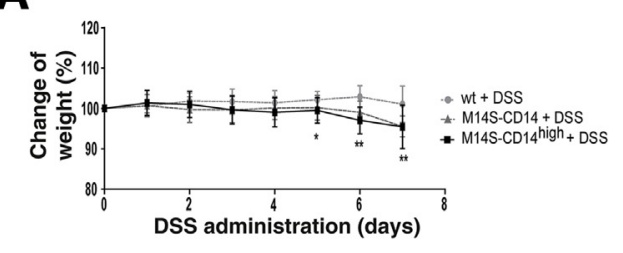

C

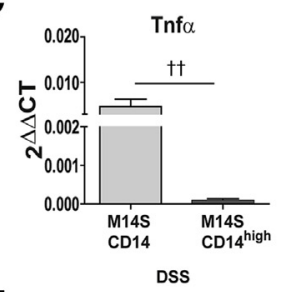

$\mathbf{F}$
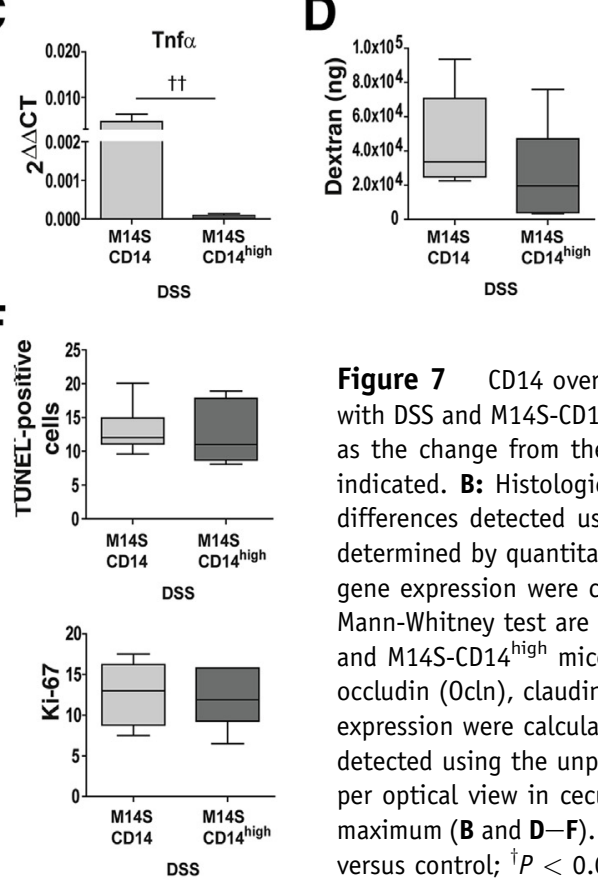

B
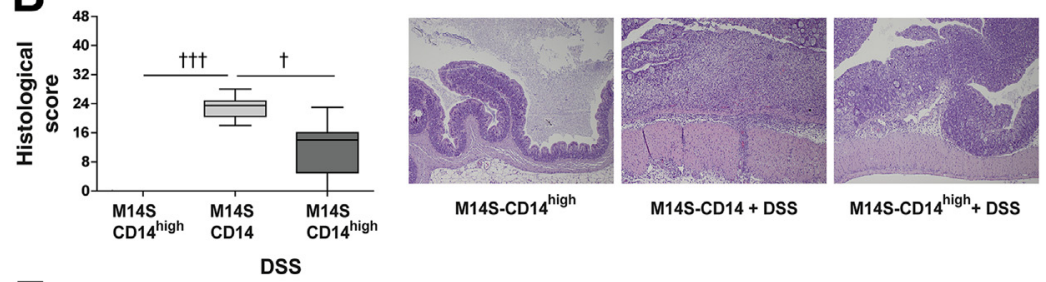

E
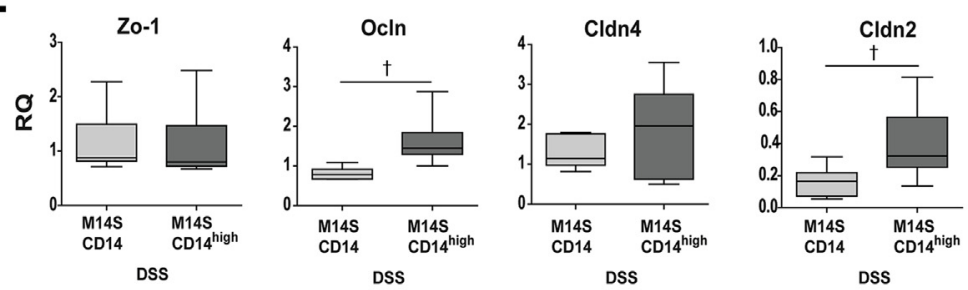

DSS

Figure 7 CD14 overexpression enhances intestinal barrier integrity. Wild-type (wt) and M14S mice were treated with DSS and M14S-CD14 ${ }^{\text {high }}$ mice with zinc sulfate/DSS. A: Body weight was measured over time and was calculated as the change from the initial body weight. Significant differences detected by two-way analysis of variance are indicated. B: Histological scores were determined to quantify the alterations observed in the colons. Significant differences detected using the Kruskal-Wallis test are indicated. C: Tumor necrosis factor (Tnf)- $\alpha$ expression was determined by quantitative RT-PCR (RT-qPCR) in colon samples from DSS-treated M14S mice. Relative differences in gene expression were calculated using the comparative $2^{-\Delta \Delta C t}$ method. Significant differences detected using the Mann-Whitney test are indicated. D: FITC-dextran uptake was measured in urine samples collected from M14S-CD14 and M14S-CD14 ${ }^{\text {high }}$ mice maintained in metabolic cages. E: RT-qPCR analysis of zonula occludens protein-1 (Zo-1), occludin (0cln), claudin-4 (Cldn4), and claudin-2 (Cldn2) expression in cecum samples. Relative differences in gene expression were calculated using a reference sample. The values are shown as fold changes. Significant differences detected using the unpaired $t$-test are indicated. F: Quantification of TUNEL-positive cells and Ki-67-positive cells per optical view in cecum samples. Data are expressed as means \pm SEM ( $\mathbf{A}$ and $\mathbf{C}$ ) or as median and minimum to maximum (B and $\mathbf{D}-\mathbf{F}) . n=9$ to $12(\mathbf{A}) ; n=8$ to $11(\mathbf{B}) ; n=6$ to 7 (C and $\mathbf{E}) ; n=5$ to 6 (D); $n=6(\mathbf{F})$. ${ }^{*} P<0.05$ versus control; ${ }^{\dagger} P<0.05,{ }^{\dagger \dagger} P<0.01$, and ${ }^{\dagger \dagger} P<0.001$. Original magnification, $\times 5$ (B).

This resulted in the NF- $\kappa \mathrm{B}$ activation ${ }^{12,30}$ and in increased barrier permeability. ${ }^{42}$ Furthermore, it was shown that a proinflammatory immune response is initiated accompanied by TNF- $\alpha$, IL-1 $\beta$, and IL- 6 production. ${ }^{43-45}$ We also found a CD14-dependent production of IL-6 after LPS treatment. Thus, sCD14 seems to have an effect on epithelial cells, influencing the barrier. In epithelial cells, NF- $\mathrm{KB}$ signaling is essential for maintaining epithelial integrity. ${ }^{19,20}$ Because stimulation of CD14/TLR4 leads to activation and nuclear translocation of NF- $\mathrm{BB},{ }^{18}$ we investigated whether CD14 was able to alter the NF- $\kappa \mathrm{B}$ activity in vitro. We found an increased NF- $\kappa$ B activation of the CMT93 cells after 0.5 hours of LPS stimulation in the presence of high CD14 concentrations. This is insofar not surprising as others showed that CD14 signaling was essential for LPS recognition of TLR4 at low LPS concentrations (up to $100 \mathrm{ng}$ / $\mathrm{mL}) .{ }^{46,47}$ However, at high LPS concentrations or in the presence of live bacteria, CD14 is not necessary for TLR4 activation. ${ }^{46,47}$ Thus, CD14 plays an important role in sensitizing for LPS-mediated NF- $\kappa \mathrm{B}$ activation.

$C d 14^{-1-}$ mice have been used in different studies to examine the role of CD14 in intestinal barrier integrity. In our hands, the intestinal epithelial barriers of specified pathogen-free housed $C d 14^{-/}$mice were functionally intact, as demonstrated by the similar expression levels of various TJ molecules, as well as the similar proliferation and cell death rates, compared with those of wild-type mice under steady-state conditions. Similar results regarding proliferation and barrier integrity under steady-state conditions have been reported in $\mathrm{TLR}^{-1-}$ and $\mathrm{MyD} 88^{-1-}$ mice. ${ }^{48,49}$ However, the Zo-1 expression has not been found to increase in germ-free $C d 14^{-\prime-}$ mice after $E c N$ inoculation, like it was the case in wt mice. This is consistent with Ukena et al, ${ }^{50}$ who showed an up-regulation of Zo-1 in the intestinal epithelial cells of gnotobiotic mice after $E c N$ monoassociation. $E c N$ is a well-described probiotic bacterium that is known to improve the intestinal barrier function in the DSS colitis model. ${ }^{50}$ Although $E c N$ is nonpathogenic in general, we previously showed that germ-free $\mathrm{C} 3 \mathrm{H} /$ HeJZtm mice develop severe clinical symptoms after $E c N$ monoassociation, such as serositis and typhlitis. ${ }^{51}$ The $\mathrm{C} 3 \mathrm{H} /$ HeJZtm strain is lacking a functional TLR4 and so $E c N$ became an interesting target to study TLR4-related barrier factors. Consistent with the high susceptibility of the TLR4defective mice, Cd14-deficient mice exhibited colonyforming units in the spleen after $E c N$ monoassociation, whereas wt mice did not. However, the bacterial load in the mesenteric lymph nodes did not differ between the groups. The mechanism of bacterial translocation to the spleen of Cd14-deficient mice has to be further elucidated to 

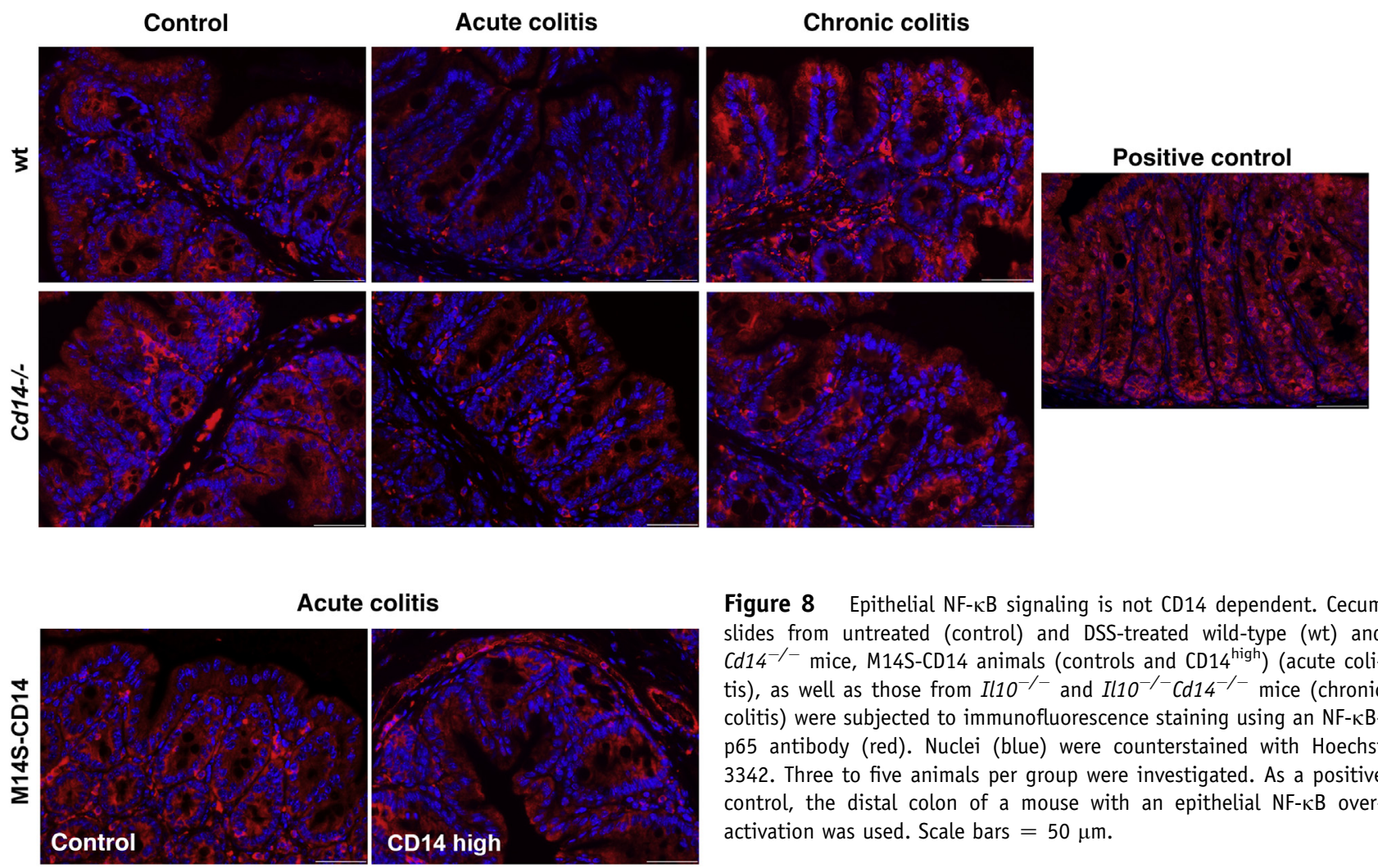

Figure 8 Epithelial NF- $\kappa$ B signaling is not CD14 dependent. Cecum slides from untreated (control) and DSS-treated wild-type (wt) and Cd14 ${ }^{-/-}$mice, M14S-CD14 animals (controls and CD14 $4^{\text {high }}$ ) (acute colitis), as well as those from $\mathrm{I}\left(1 \mathrm{O}^{-/-}\right.$and $\mathrm{I}\left(1 \mathrm{O}^{-/-} \mathrm{Cd} 14^{-{ }^{-}}\right.$mice (chronic colitis) were subjected to immunofluorescence staining using an NF-KBp65 antibody (red). Nuclei (blue) were counterstained with Hoechst 3342. Three to five animals per group were investigated. As a positive control, the distal colon of a mouse with an epithelial NF- $\kappa B$ overactivation was used. Scale bars $=50 \mu \mathrm{m}$.

distinguish between TJ-related or extraintestinal processes. Thus, under steady-state conditions, intestinal barrier integrity seems to change to adapt to the environmental conditions, whereas environmental alterations may not lead to rapid changes in mice lacking $C d 14$.

The intestinal barriers were disrupted in the $\mathrm{Cd} 14^{-/-}$ mice after the DSS treatment, and these barriers could not be restored. The $\mathrm{Cd}_{1} 4^{-1-}$ mice lost weight and showed increases in intestinal inflammation and proinflammatory cytokine expression. The expression levels of TJ proteins were reduced and the rates of dead cells in the lamina propria were increased, resulting in enhanced barrier permeability. Ki-67 staining revealed an increase of proliferating cells in the lamina propria, which probably represent infiltrating immune cells and do not imply an improved barrier function. Previous data from our group have
A

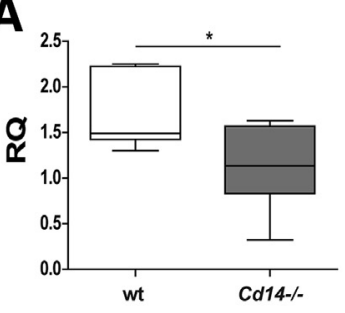

D

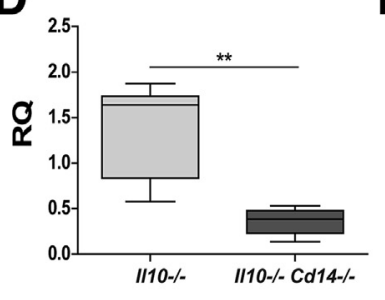

B

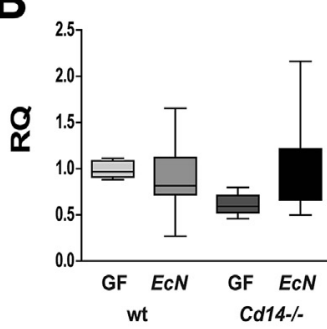

$\mathbf{E}$

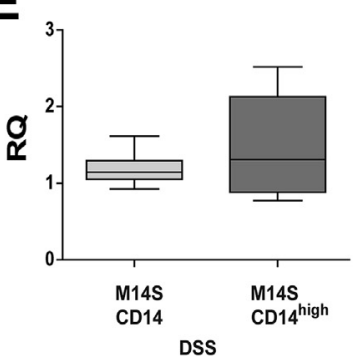

C

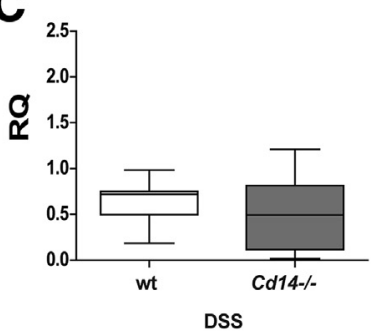

DSS

Figure 9 Intestinal myosin light chain kinase (Mlck) expression in Cd14-deficient and CD14overexpressing mice. Mlck expression was determined by quantitative RT-PCR in colon samples from all analyzed mouse models [steady state (A), EcN monoassociation (B), acute colitis (C), chronic colitis (D), and CD14 overexpression (E)]. Relative differences in gene expression were calculated using a reference sample. Data are expressed as fold changes (median and minimum to maximum). $n=5$ to 8 (A-E). ${ }^{*} P<0.05,{ }^{*} P<<0.01$ (unpaired $t$-test). wt, wild-type. 
indicated that CD14 plays a pivotal role in intestinal barrier function during acute DSS colitis, as demonstrated by the extent of ulcerations in $\mathrm{Cd} 14^{-/-}$mice. ${ }^{9} \mathrm{CD} 14$ is a coreceptor for TLR4 involved in LPS recognition, which leads to activation of the MyD88 pathway, and $\mathrm{TLR}^{-1-}$ and MyD88 ${ }^{-1-}$ mice have been shown to be highly susceptible to DSS-induced colitis. ${ }^{52,53}$ However, other studies have not been able to repeat these findings. ${ }^{48,54}$

The $1 l 10^{-1-} \mathrm{Cd} 14^{-1-}$ mice, which developed chronic inflammation, exhibited more severe intestinal lesions and ulcerations compared to the $I l 10^{-/-}$mice. The expression of TJ proteins was reduced, and the number of dead cells was increased. Under chronic inflammatory conditions, the lack of CD14 seems to have similar effects on TJ permeability as those observed in the acute model. Therefore, the presence of CD14 seems less important when the epithelial layer is not disturbed. Nevertheless, our data provide evidence that after LPS stimulation, epithelial breakdown, or epithelial damage, CD14 is needed to maintain or reestablish intestinal homeostasis.

Finally, examination of the DSS-treated CD14overexpressing mice revealed clear barrier improvement and less histological tissue damage, attributed to the high CD14 concentration present. These findings are corroborated by our previous results obtained using $\mathrm{Cd} 14$-deficient CMT93 cells, ${ }^{30}$ in which sCD14 seems to improve cell barrier integrity during LPS treatment. Consistent with these findings, colonic Tnf- $\alpha$ expression was significantly lower in the DSS-treated CD14-overexpressing mice than in the controls. Thus, sCD14 seems to improve barrier function.

As mentioned above, stimulation of CD14/TLR4 leads to activation and nuclear translocation of NF- $\kappa \mathrm{B},{ }^{18}$ which is essential for maintaining barrier function in intestinal epithelial cells. ${ }^{19,20}$ The in vitro data of the CMT93 cells revealed a higher sensitivity to LPS in the presence of CD14. Therefore, we investigated whether decreased epithelial NF- $\kappa \mathrm{B}$ signaling may cause barrier impairment in $C d 14^{-1-}$ mice or increased activation could lead to a retightening of the epithelial barrier in the CD14overexpressing mouse model. As expected, strong nuclear NF- $\kappa \mathrm{B}$ signaling was detected in inflamed tissues from all mice compared to uninflamed tissues under steady-state conditions mapped by a higher nuclear fluorescence signal of the immune cells located in the lamina propria. However, only a slight signal was detectable in the epithelial cells and no differences in activation were observed between the $C d 14^{-1-}$ and wt mice as well as CD14-overexpressing and control animals. Thus, altered epithelial NF- $\kappa \mathrm{B}$ signaling does not seem to be responsible for the reduced barrier function in $\mathrm{Cd} 14$-deficient mice or the barrier improvement within the CD14-overexpressing mouse model.

Proinflammatory cytokines, such as TNF- $\alpha$ and IFN- $\gamma$, are other well-known barrier regulators. ${ }^{32-34}$ Both of these cytokines decrease epithelial integrity by down-regulating occludin and claudin-4 expression. Therefore, their expression was assessed in colonic tissues in the present study. Expression of these cytokines did not differ between the
$C d 14^{-/-}$mice and wild-type controls under steady-state conditions; however, Ifn- $\gamma$ expression was significantly increased in the DSS-treated $\mathrm{Cdl}^{-1-}$ mice in the acute colitis model. Likewise, Tnf- $\alpha$ and Ifn- $\gamma$ expression was significantly increased in the $1110^{-/-} \mathrm{Cd}_{14^{-/-}}$mice compared with the controls in the chronic model of intestinal inflammation; this finding is consistent with previously published data. ${ }^{44,55}$ This increased proinflammatory cytokine expression could be likely the reason for the barrier impairment, with CD14 acting indirectly by down-regulating barrierdisturbing factors. TNF- $\alpha$ signals through two receptors both expressed on intestinal epithelial cells: The TNFR1 is more important in the context of cell death, and TNFR2 increases barrier permeability by up-regulating the epithelial Mlck expression after NF- $\mathrm{\kappa B}$ activation. ${ }^{35,56} \mathrm{IFN}-\gamma$ acts synergistically and is able to increase the TNF- $\alpha$ receptor expression. $^{57}$ Therefore, TNF- $\alpha-$ and IFN- $\gamma-$ mediated Mlck up-regulation could be the underlying mechanism of CD14dependent barrier regulation. Surprisingly, we found a decreased Mlck expression in the Cdl4-deficient mice already under steady-state conditions, although no differences in Tnf- $\alpha$ expression were observed. Furthermore, decreased Mlck expression was also measured in the chronic colitis model, but no differences in the DSS colitis models were detected, independent of CD14. Although the intestinal permeability and the Mlck expression were found to be up-regulated in the context of colitis, ${ }^{35,58}$ a direct relationship of Mlck expression and barrier integrity was missing in our study. Other processes induced by TNF- $\alpha$ are cell death pathways, such as apoptosis and necroptosis. ${ }^{56}$ As we observed an increased number of TUNEL-positive cells in Cd14-deficient mice in both models of colitis, the barrier impairment could be because of a higher number of dying cells. However, no decrease of TUNEL-positive cells could be observed in the CD14-overexpressing mice compared to controls after DSS treatment. High zinc concentrations could induce cell death in intestinal epithelial cells. ${ }^{59}$ Therefore, the oral zinc treatment could cause cell death in the CD14overexpressing mice and so obscure a possibly decreased cell death rate.

Besides MyD88, the adaptor molecule TIRdomain-containing adapter-inducing interferon- $\beta$ also takes part in TLR4 signaling. ${ }^{60} \mathrm{CD} 14$ was shown to be indispensable for TLR4 signaling through TIRdomain-containing adapter-inducing interferon- $\beta$, whereas MyD88 did not require the presence of CD14. ${ }^{60}$ Therefore, the TIR-domain-containing adapter-inducing interferon$\beta$-dependent pathway could also be an interesting effector molecule in the context of CD14-dependent barrier regulation. Further studies are now necessary to understand the influence of sCD14 on barrier function and to elucidate the underlying mechanism.

In summary, this study has clearly demonstrated a supportive role of CD14 in barrier integrity, as well as protective roles in experimental acute and chronic colitis. Lack of CD14 resulted in increased proinflammatory cytokine 
expression and decreased expression of TJ molecules after barrier disruption in both the acute and chronic inflammation models. Barrier integrity was sustained by CD14 overexpression. Therefore, CD14 might be an interesting target for future clinical research.

\section{Acknowledgments}

We thank Andrea Liese, Anna Smoczek, Anja Siebert, Stefan Wallmüller, Kristina Urbanova, and Elena Wiebe for their excellent technical assistance.

\section{Supplemental Data}

Supplemental material for this article can be found at http://dx.doi.org/10.1016/j.ajpath.2017.01.012.

\section{References}

1. Keubler LM, Buettner M, Hager C, Bleich A: A multihit model: colitis lessons from the interleukin-10-deficient mouse. Inflamm Bowel Dis 2015, 21:1967-1975

2. Ek WE, D'Amato M, Halfvarson J: The history of genetics in inflammatory bowel disease. Ann Gastroenterol 2014, 27:294-303

3. Anderson CA, Massey DC, Barrett JC, Prescott NJ, Tremelling M, Fisher SA, Gwilliam R, Jacob J, Nimmo ER, Drummond $\mathrm{H}$, Lees CW, Onnie CM, Hanson C, Blaszczyk K, Ravindrarajah R, Hunt S, Varma D, Hammond N, Lewis G, Attlesey H, Watkins N, Ouwehand W, Strachan D, McArdle W, Lewis CM, Wellcome Trust Case Control Consortium, Lobo A, Sanderson J, Jewell DP, Deloukas P, Mansfield JC, Mathew CG, Satsangi J, Parkes M: Investigation of Crohn's disease risk loci in ulcerative colitis further defines their molecular relationship. Gastroenterology 2009, 136: 523-529.e3

4. Fisher SA, Tremelling M, Anderson CA, Gwilliam R, Bumpstead S, Prescott NJ, Nimmo ER, Massey D, Berzuini C, Johnson C, Barrett JC, Cummings FR, Drummond H, Lees CW, Onnie CM, Hanson CE, Blaszczyk K, Inouye M, Ewels P, Ravindrarajah R, Keniry A, Hunt S, Carter M, Watkins N, Ouwehand W, Lewis CM, Cardon L; Wellcome Trust Case Control Consortium, Lobo A, Forbes A, Sanderson J, Jewell DP, Mansfield JC, Deloukas P, Mathew CG, Parkes M, Satsangi J: Genetic determinants of ulcerative colitis include the ECM1 locus and five loci implicated in Crohn's disease. Nat Genet 2008, 40:710-712

5. Mähler M, Most C, Schmidtke S, Sundberg JP, Li R, Hedrich HJ, Churchill GA: Genetics of colitis susceptibility in IL-10-deficient mice: backcross versus F2 results contrasted by principal component analysis. Genomics 2002, 80:274-282

6. Farmer MA, Sundberg JP, Bristol IJ, Churchill GA, Li R, Elson CO, Leiter EH: A major quantitative trait locus on chromosome 3 controls colitis severity in IL-10-deficient mice. Proc Natl Acad Sci U S A 2001, 98:13820-13825

7. de Buhr MF, Mähler M, Geffers R, Hansen W, Westendorf AM, Lauber J, Buer J, Schlegelberger B, Hedrich HJ, Bleich A: Cd14, Gbp1, and Pla2g2a: three major candidate genes for experimental IBD identified by combining QTL and microarray analyses. Physiol Genomics 2006, 25:426-434

8. Kamada N, Hisamatsu T, Okamoto S, Chinen H, Kobayashi T, Sato T, Sakuraba A, Kitazume MT, Sugita A, Koganei K, Akagawa KS, Hibi T: Unique CD14 intestinal macrophages contribute to the pathogenesis of Crohn disease via IL-23/IFN-gamma axis. J Clin Invest 2008, 118:2269-2280
9. de Buhr MF, Hedrich HJ, Westendorf AM, Obermeier F, Hofmann C, Zschemisch NH, Buer J, Bumann D, Goyert SM, Bleich A: Analysis of $\mathrm{Cd} 14$ as a genetic modifier of experimental inflammatory bowel disease (IBD) in mice. Inflam Bowel Dis 2009, 15:1824-1836

10. Beitnes AC, Raki M, Brottveit M, Lundin KE, Jahnsen FL, Sollid LM: Rapid accumulation of CD14+CD11c + dendritic cells in gut mucosa of celiac disease after in vivo gluten challenge. PLoS One 2012, 7:e33556

11. Antal-Szalmas P, Strijp JA, Weersink AJ, Verhoef J, Van Kessel KP: Quantitation of surface CD14 on human monocytes and neutrophils. J Leukoc Biol 1997, 61:721-728

12. Zanoni I, Granucci F: Role of CD14 in host protection against infections and in metabolism regulation. Front Cell Infect Microbiol 2013, 3:32

13. Kitchens RL, Thompson PA: Modulatory effects of sCD14 and LBP on LPS-host cell interactions. J Endotoxin Res 2005, 11: 225-229

14. Thiesen S, Janciauskiene S, Uronen-Hansson H, Agace W, Hogerkorp CM, Spee P, Hakansson K, Grip O: CD14(hi)HLADR(dim) macrophages, with a resemblance to classical blood monocytes, dominate inflamed mucosa in Crohn's disease. J Leukoc Biol 2014, 95:531-541

15. Shen L, Weber CR, Raleigh DR, Yu D, Turner JR: Tight junction pore and leak pathways: a dynamic duo. Annu Rev Physiol 2011, 73: 283-309

16. Turner JR: Intestinal mucosal barrier function in health and disease. Nat Rev Immunol 2009, 9:799-809

17. Barreau F, Hugot JP: Intestinal barrier dysfunction triggered by invasive bacteria. Curr Opin Microbiol 2014, 17:91-98

18. Akira S, Hoshino K: Myeloid differentiation factor 88-dependent and -independent pathways in toll-like receptor signaling. J Infect Dis 2003, 187(Suppl 2):S356-S363

19. Steinbrecher KA, Harmel-Laws E, Sitcheran R, Baldwin AS: Loss of epithelial RelA results in deregulated intestinal proliferative/apoptotic homeostasis and susceptibility to inflammation. J Immunol 2008, 180:2588-2599

20. Nenci A, Becker C, Wullaert A, Gareus R, van Loo G, Danese S, Huth M, Nikolaev A, Neufert C, Madison B, Gumucio D, Neurath MF, Pasparakis M: Epithelial NEMO links innate immunity to chronic intestinal inflammation. Nature 2007, 446:557-561

21. Tamura Y, Higuchi Y, Kataoka M, Akizuki S, Matsuura K, Yamamoto S: CD14 transgenic mice expressing membrane and soluble forms: comparisons of levels of cytokines and lethalities in response to lipopolysaccharide between transgenic and nontransgenic mice. Int Immunol 1999, 11:333-339

22. Hoesel B, Schmid JA: The complexity of NF-kappaB signaling in inflammation and cancer. Mol Cancer 2013, 12:86

23. Janus LM, Smoczek A, Jorns A, Hedrich HJ, Bleich A: Presence of Minute virus of mice in immunocompetent mice despite the onset of host immunity. Vet Microbiol 2010, 146:51-58

24. Bleich A, Mähler M, Most C, Leiter EH, Liebler-Tenorio E, Elson CO, Hedrich HJ, Schlegelberger B, Sundberg JP: Refined histopathologic scoring system improves power to detect colitis QTL in mice. Mamm Genome 2004, 15:865-871

25. Hager C, Keubler LM, Biernot S, Dietrich J, Buchheister S, Buettner M, Bleich A: Time to integrate to Nest Test evaluation in a mouse DSS-colitis model. PLoS One 2015, 10:e0143824

26. Bleich EM, Leonhard-Marek S, Beyerbach M, Breves G: Characterisation of chloride currents across the proximal colon in CftrTgH(neoim)1Hgu congenic mice. J Comp Physiol B 2007, 177: $61-73$

27. Toth B, Leonhard-Marek S, Hedrich HJ, Breves G: Characterisation of electrogenic nutrient absorption in the $\mathrm{Cftr} \mathrm{TgH}$ (neoim)Hgu mouse model. J Comp Physiol B 2008, 178:705-712

28. Schroeder B, Duncker S, Barth S, Bauerfeind R, Gruber AD, Deppenmeier S, Breves G: Preventive effects of the probiotic 
Escherichia coli strain Nissle 1917 on acute secretory diarrhea in a pig model of intestinal infection. Dig Dis Sci 2006, 51:724-731

29. Schultz SG, Zalusky R: Ion transport in isolated rabbit ileum, I: shortcircuit current and Na fluxes. J Gen Physiol 1964, 47:567-584

30. Cario E, Rosenberg IM, Brandwein SL, Beck PL, Reinecker HC, Podolsky DK: Lipopolysaccharide activates distinct signaling pathways in intestinal epithelial cell lines expressing Toll-like receptors. J Immunol 2000, 164:966-972

31. Guo S, Al-Sadi R, Said HM, Ma TY: Lipopolysaccharide causes an increase in intestinal tight junction permeability in vitro and in vivo by inducing enterocyte membrane expression and localization of TLR-4 and CD14. Am J Pathol 2013, 182:375-387

32. Al-Sadi R, Boivin M, Ma T: Mechanism of cytokine modulation of epithelial tight junction barrier. Front Biosci (Landmark Ed) 2009, 14: $2765-2778$

33. Wang F, Graham WV, Wang Y, Witkowski ED, Schwarz BT, Turner JR: Interferon-gamma and tumor necrosis factor-alpha synergize to induce intestinal epithelial barrier dysfunction by upregulating myosin light chain kinase expression. Am J Pathol 2005, 166:409-419

34. Ye D, Guo S, Al-Sadi R, Ma TY: MicroRNA regulation of intestinal epithelial tight junction permeability. Gastroenterology 2011, 141: 1323-1333

35. Su L, Nalle SC, Shen L, Turner ES, Singh G, Breskin LA, Khramtsova EA, Khramtsova G, Tsai PY, Fu YX, Abraham C, Turner JR: TNFR2 activates MLCK-dependent tight junction dysregulation to cause apoptosis-mediated barrier loss and experimental colitis. Gastroenterology 2013, 145:407-415

36. Ortega-Cava CF, Ishihara S, Rumi MA, Kawashima K, Ishimura N, Kazumori H, Udagawa J, Kadowaki Y, Kinoshita Y: Strategic compartmentalization of Toll-like receptor 4 in the mouse gut. J Immunol 2003, 170:3977-3985

37. Sekirov I, Russell SL, Antunes LC, Finlay BB: Gut microbiota in health and disease. Physiol Rev 2010, 90:859-904

38. Artis D: Epithelial-cell recognition of commensal bacteria and maintenance of immune homeostasis in the gut. Nat Rev Immunol 2008, 8:411-420

39. Morrissey J, Guo G, McCracken R, Tolley T, Klahr S: Induction of CD14 in tubular epithelial cells during kidney disease. J Am Soc Nephrol 2000, 11:1681-1690

40. Frey EA, Miller DS, Jahr TG, Sundan A, Bazil V, Espevik T, Finlay BB, Wright SD: Soluble CD14 participates in the response of cells to lipopolysaccharide. J Exp Med 1992, 176:1665-1671

41. Hornef MW, Frisan T, Vandewalle A, Normark S, RichterDahlfors A: Toll-like receptor 4 resides in the Golgi apparatus and colocalizes with internalized lipopolysaccharide in intestinal epithelial cells. J Exp Med 2002, 195:559-570

42. Clarke TB, Francella N, Huegel A, Weiser JN: Invasive bacterial pathogens exploit TLR-mediated downregulation of tight junction components to facilitate translocation across the epithelium. Cell Host Microbe 2011, 9:404-414

43. Dentener MA, Bazil V, Von Asmuth EJ, Ceska M, Buurman WA: Involvement of CD14 in lipopolysaccharide-induced tumor necrosis factor-alpha, IL-6 and IL-8 release by human monocytes and alveolar macrophages. J Immunol 1993, 150:2885-2891

44. Perera PY, Vogel SN, Detore GR, Haziot A, Goyert SM: CD14dependent and CD14-independent signaling pathways in murine macrophages from normal and CD14 knockout mice stimulated with lipopolysaccharide or taxol. J Immunol 1997, 158:4422-4429

45. Feghali K, Tanabe S, Grenier D: Soluble CD14 induces cytokine release by human oral epithelial cells. J Periodontal Res 2011, 46:147-152
46. Lloyd-Jones KL, Kelly MM, Kubes P: Varying importance of soluble and membrane CD14 in endothelial detection of lipopolysaccharide. J Immunol 2008, 181:1446-1453

47. Moore KJ, Andersson LP, Ingalls RR, Monks BG, Li R, Arnaout MA, Golenbock DT, Freeman MW: Divergent response to LPS and bacteria in CD14-deficient murine macrophages. J Immunol 2000, 165:4272-4280

48. Fukata M, Michelsen KS, Eri R, Thomas LS, Hu B, Lukasek K, Nast CC, Lechago J, Xu R, Naiki Y, Soliman A, Arditi M, Abreu MT: Toll-like receptor-4 is required for intestinal response to epithelial injury and limiting bacterial translocation in a murine model of acute colitis. Am J Physiol Gastrointest Liver Physiol 2005, 288: G1055-G1065

49. Slack E, Hapfelmeier S, Stecher B, Velykoredko Y, Stoel M, Lawson MA, Geuking MB, Beutler B, Tedder TF, Hardt WD, Bercik P, Verdu EF, McCoy KD, Macpherson AJ: Innate and adaptive immunity cooperate flexibly to maintain host-microbiota mutualism. Science 2009, 325:617-620

50. Ukena SN, Singh A, Dringenberg U, Engelhardt R, Seidler U, Hansen W, Bleich A, Bruder D, Franzke A, Rogler G, Suerbaum S, Buer J, Gunzer F, Westendorf AM: Probiotic Escherichia coli Nissle 1917 inhibits leaky gut by enhancing mucosal integrity. PLoS One 2007, 2:e1308

51. Bleich A, Sundberg JP, Smoczek A, von Wasielewski R, de Buhr MF, Janus LM, Julga G, Ukena SN, Hedrich HJ, Gunzer F: Sensitivity to Escherichia coli Nissle 1917 in mice is dependent on environment and genetic background. Int J Exp Pathol 2008, 89:45-54

52. Rakoff-Nahoum S, Paglino J, Eslami-Varzaneh F, Edberg S, Medzhitov R: Recognition of commensal microflora by toll-like receptors is required for intestinal homeostasis. Cell 2004, 118: 229-241

53. Araki A, Kanai T, Ishikura T, Makita S, Uraushihara K, Iiyama R, Totsuka T, Takeda K, Akira S, Watanabe M: MyD88-deficient mice develop severe intestinal inflammation in dextran sodium sulfate colitis. J Gastroenterol 2005, 40:16-23

54. Grabig A, Paclik D, Guzy C, Dankof A, Baumgart DC, Erckenbrecht J, Raupach B, Sonnenborn U, Eckert J, Schumann RR, Wiedenmann B, Dignass AU, Sturm A: Escherichia coli strain Nissle 1917 ameliorates experimental colitis via toll-like receptor 2- and toll-like receptor 4dependent pathways. Infect Immun 2006, 74:4075-4082

55. Sahay B, Patsey RL, Eggers CH, Salazar JC, Radolf JD, Sellati TJ: CD14 signaling restrains chronic inflammation through induction of p38-MAPK/SOCS-dependent tolerance. PLoS Pathog 2009, 5: e1000687

56. Leppkes M, Roulis M, Neurath MF, Kollias G, Becker C: Pleiotropic functions of TNF-alpha in the regulation of the intestinal epithelial response to inflammation. Int Immunol 2014, 26:509-515

57. Beaurepaire C, Smyth D, McKay DM: Interferon-gamma regulation of intestinal epithelial permeability. J Interferon Cytokine Res 2009, 29:133-144

58. Xiao YT, Yan WH, Cao Y, Yan JK, Cai W: Neutralization of IL-6 and TNF-alpha ameliorates intestinal permeability in DSS-induced colitis. Cytokine 2016, 83:189-192

59. Cario E, Jung S, Harder D'Heureuse J, Schulte C, Sturm A, Wiedenmann B, Goebell H, Dignass AU: Effects of exogenous zinc supplementation on intestinal epithelial repair in vitro. Eur J Clin Invest 2000, 30:419-428

60. Jiang Z, Georgel P, Du X, Shamel L, Sovath S, Mudd S, Huber M, Kalis C, Keck S, Galanos C, Freudenberg M, Beutler B: CD14 is required for MyD88-independent LPS signaling. Nat Immunol 2005, 6:565-570 